\title{
Evolving Interpretations of Human Rights
}

\author{
Shirley Gatenio Gabel ${ }^{1} \cdot$ Susan Mapp ${ }^{2}$
}

Published online: 15 September 2017

(C) Springer International Publishing AG 2017

The contributions in this issue make clear that our interpretations of human rights are constantly evolving. This may be due to changing societal contexts, technology and awareness of who is vulnerable to human rights abuses and to new potentials for violations. Human rights law must be responsive to our changing ideas and understanding of human rights practice. At the same time, laws and professional standards clearly shape rights-based social work practice.

In this issue, our contributors look at how established human rights laws and professional standards can promote the realization of human rights.

Two of the articles directly call for the establishment of international human rights standards. The first article by leading child welfare experts, Rotabi, Mapp, Cheney, Fong, and McRoy, explores the rise in commercial global surrogacy over the past decade and the lack of international law to reconcile conflicting national laws and protect the interests of infant/ child, surrogate mother, and commissioning parent(s). Previous discussions have considered the vulnerability of the surrogate mothers but not enough attention has been given to the best interests of the child who is born into this world as a

Shirley Gatenio Gabel

gateniogabe@fordham.edu

Susan Mapp

mapps@etown.edu

1 Fordham University, New York, NY, USA

2 Department of Social Work, Elizabethtown College, Elizabethtown, PA, USA result of surrogacy. Some of these children are left stateless due to incongruent laws and policies across countries.

At the other end of the life spectrum, Cox and Pardasani advocate for an international human rights convention specifically addressing the rights of older adults. Due to physiological, social, and economic changes, many older adults find themselves vulnerable and in need of protection. The authors suggest ways in which using a rights-based approach framed by a UN Convention can enhance social work practice at the micro, mezzo, and macro levels and contribute to the wellbeing of older adults.

In another article regarding older adults, Kusmaul, BernKlug, and Bonifas look at older adults who are institutionalized in nursing homes and the ways in which their rights can be compromised. Focusing on practice issues, the authors suggest ways in which social workers can realize and respect the dignity of nursing home residents by altering practices to follow rights-based approaches and suggest ways that the Social Work Code of Ethics should be amended to more fully promote rights.

Martinez Herrero and Nicholls remind us that the existence of laws and normative standards is not enough to promote rights. Using human rights law in the UK, the authors argue that UK law has narrowed conceptualizations of human rights-based social work practice and needs to be replaced with broader conceptualizations of human rights law that allow for fuller social work practices.

Together, these articles make the point that human rights are not a settled concept and that evolutions in society require continuing conversations to ensure that human rights are met for all. However, even once rights are guaranteed in law, ongoing work is required to ensure they are realized. 